\title{
Being autonomous and having space in which to act: commissioning in the 'new NHS' in England
}

\author{
Kath Checkland $^{1}$ (Corresponding author) \\ Rinita Dam ${ }^{1}$ \\ Jon Hammond ${ }^{1}$ \\ Anna Coleman ${ }^{1}$ \\ Julia Segar ${ }^{1}$ \\ Nicholas Mays ${ }^{2}$ \\ Pauline Allen ${ }^{2}$
}

1. Centre for Primary Care, Division of Population Health, Health Services Research and Primary Care, School of Health Sciences, Faculty of Biology, Medicine and Health, University of Manchester, Oxford Road, Manchester M13 9PL

2. Department of Health Services Research and Policy, Faculty of Public Health and Policy, London School of Hygiene and Tropical Medicine, 15-17 Tavistock Place, London WC1H 9SH

\section{Acknowledgements/disclaimer}

We are grateful to our participants, who were very generous with their time. The study was funded by the Department of Health via the Policy research Programme. The views expressed here represent those of the authors, not the Department of Health.

Sadly, since this paper was submitted, our co-author, Julia Segar, has died. She was an inspirational colleague, and the ideas expressed here owe a big debt to her insight and intellectual rigour. 


\title{
Being autonomous and having space in which to act: commissioning in the 'new NHS' in England
}

\begin{abstract}
The optimal balance between central governmental authority and the degree of autonomy of local public bodies is an enduring issue in public policy. The UK National Health Service is no exception, with NHS history, in part at least, a history of repeated cycles of centralisation and decentralisation of decision making power. Most recently, a significant reorganisation of the NHS in 2102-13 was built around the creation of new and supposedly more autonomous commissioning organisations (Clinical Commissioning Groups - CCGs). Using Bossert's (1998) concept of 'decision space', we explore the experiences of local commissioners as they took on their new responsibilities. We interviewed commissioning staff from all of the CCGs in two regional health care 'economies', exploring their perceptions of autonomy and their experiences over time. We found significant early enthusiasm for, and perceptions of, increased autonomy tempered in the vertical dimension by increasingly onerous and prescriptive monitoring regimes, and in the horizontal dimension by the proliferation of overlapping networks, inter-organisational groups and relationships. We propose that whatever the balance between central and local control that is adopted, complex public services require some sort of meso-level oversight from organisations able to 'hold the ring' between competing interests and to take a regional view of the needs of the local health system. This suggests that local organisational autonomy in such services will always be constrained.
\end{abstract}

Keywords:

Commissioning; NHS; decentralisation; autonomy; decision space; Clinical Commissioning Groups

\section{INTRODUCTION}

The extent to which local public bodies should be autonomous and have decentralised authority to act as they deem most appropriate is one of the enduring puzzles in the field of public policy. De Vries (2000) explores the arguments in favour of both centralisation and decentralisation, and concludes that, not only are their outcomes highly context-dependent, but also that, in some circumstances, the same arguments can be used in favour of both. He identifies 'cycles' of political centralisation/decentralisation in a number of European countries, and highlights the extent to which the interests of local elites may influence the arguments made. Such cycles (or 'pendulum swings' (Axelsson, 2000)) are particularly visible in the field of health care policy internationally (Mosca, 2005), and the NHS in the UK is no exception. Klein notes that: 'In setting up the NHS, the aim was to reconcile national accountability and local autonomy' (Klein, 2013 p35). In the years since 1948, the NHS has continued to wrestle with this conundrum, with repeated reorganisations motivated, in part at least, by the need to manage the tension between operational efficiency and 
responsiveness to local needs (assumed to be supported by local autonomy) and central control (Exworthy et al., 2010).

In the last five years the NHS in England has been undergoing a period of unprecedented structural change (Timmins, 2012). The 2012 Health and Social Care Act (HSCA12) designed and championed by the then Secretary of State, Andrew Lansley - significantly altered its architecture, abolishing and creating organisations, and shifting responsibilities in fundamental ways. A stated desire to increase local autonomy by 'empowering' clinical professionals was said to lie at the heart of the reforms:

"The Government's reforms will empower professionals and providers, giving them more autonomy and, in return, making them more accountable for the results they achieve, accountable to patients through choice and accountable to the public at local level." (Department of Health, 2010, para 6.0).

To achieve this aim, the HSCA12 abolished Primary Care Trusts (PCTs), which were previously responsible for commissioning (i.e. assessing health care need, and planning and purchasing the services to meet that need) the majority of care required by a geographical population, and transferred their responsibilities to newly established Clinical Commissioning Groups (CCGs). These organisations were led by primary care physicians (GPs), and were designated as 'membership organisations', with every GP practice in England required to join one. CCGs are overseen by an arm's length body, known as NHS England, which is also responsible for commissioning some highly specialised services (Checkland et al., 2016a). Crucially, the reforms stripped out a regional tier of governance known as Strategic Health Authorities (SHA), which had been responsible for overseeing the interactions between commissioners and providers within their geographical areas. The HSCA12 abolished SHAs, arguing that a decentralised system built around autonomous local commissioning organisations operating within a transparent national accountability framework would be more efficient, effective and innovative, and thus would not require any regional coordination or supervision (Department of Health, 2010).

The changes embodied in the HSCA12 were profound and far-reaching, affecting every level and every organisation in the NHS. Identifying the 'programme theories' (Weiss, 1999) and policy intentions underlying the Act is therefore a complex undertaking, with multiple relevant theories discernible in the extensive policy documentation issued to explain the changes and support their implementation (for examples, see NHS England, 2012). Some authors have been highly critical, arguing that, notwithstanding these expressed policy intentions:

The Health and Social Care Act is clearly an ideologically motivated piece of government reform, intended to undermine professional dominance, to inculcate private providers (to the exclusion of public providers) into statutory health care, to further inculcate discourses of public distrust in professional groups and to absolve the state of much of its statutory health care obligation. (Speed and Gabe, 2013 p 572)

From this perspective, and in the context of a crisis in the public finances, it could be argued that the strong focus on local autonomy was calculated at least in part to serve the purpose of insulating the Government from the consequences of cuts to services (Powell, 2016 p25). 
However, in his comprehensive narrative of how the initial White Paper and subsequent Act of Parliament came into being, Timmins (2012) highlights the fact that Andrew Lansley, the architect of the reforms, had published a policy paper on the NHS in 2007 which emphasised the need to give GP commissioners greater power and autonomy. Written at a time of relative plenty, and before the global financial crisis of 2008, this implies that, for Lansley at least, local commissioner autonomy was an important mechanism for service improvement over and above any political benefits that might ensue.

In this paper, we address this latest swing of the pendulum between central and local authority in the English NHS. We explore how the explicit intentions in the 2012 Act to establish more autonomous local commissioning organisations played out, examining the extent to which CCGs perceive themselves to be autonomous and able to act within the new system. To do this we utilise the 'decision space' framework, first developed by Bossert (1998) and adapted by Exworthy and Frosini (2008) and Exworthy et al. (2011), drawing on data from a study of the post-HSCA12 commissioning system in England. The contribution that we offer is twofold. Firstly, we provide new empirical evidence about the impact of one of the most significant structural reorganisations the NHS has ever seen. Secondly, we suggest that viewing complicated modern health systems through a lens which dichotomously sets local autonomy against central control risks underestimating the importance of mesolevel regional co-ordination.

It is important to make a distinction between clinical and managerial autonomy in the context of the NHS (Harrison and Ahmad, 2000). Clinical autonomy refers to the extent to which clinicians can act as they see fit in caring for their patients. We focus on managerial autonomy which, in this context, we define as the ability for commissioners to exercise autonomy over planning, financial and operational priorities within their CCGs. We demonstrate how CCGs' early sense of managerial autonomy and freedom to act was eroded over time.

\section{Context and history: autonomy and decision space}

The Cambridge online dictionary (Cambridge online)_defines autonomy as follows:

- the right of an organization, country, or region to be independent and govern itself,

- the ability to make your own decisions without being controlled by anyone else.

Thus, the concept of autonomy carries within it two aspects: freedom to make decisions or act; and freedom from external control (Verhoest et al., 2004). Exworthy et al. (2011), explore autonomy in the context of NHS Foundation Trust hospitals in England and suggest that 'freedom from' implies a degree of vertical decentralisation, with authority devolved from the centre to the local level, whilst 'freedom to' also encompasses the notion of local organisations free to act in ways responsive to local needs. Exworthy et al. (2011) argue that the latter includes the idea of freedom within 'horizontal' local organisational interdependencies.

Bossert (1998) provides an analytical framework that can be used to evaluate the decentralisation of health systems. Bossert explains the range of choices available to local 
decision-makers along a series of functional dimensions shaping local decision-making which, in turn, shape local performance. He terms this 'decision space', and uses the concept to analyse the three key elements of decentralisation:

- "the amount of choice that is transferred from central institutions to institutions at the periphery of health systems;

- what choices local officials make with their increased discretion; and

- what effect these choices have on the performance of the health system" (Bossert, 1998 p1513).

Thus, according to Bossert, 'decision space' represents the freedom granted by central government to local organisations (in this case, local NHS actors) to make choices (Figure 1).

\section{[Figure 1 near here]}

Whether or not change occurs depends upon the use made of this 'space' by local actors, which in turn is affected by the characteristics of the local organisations. We focus upon the first of Bossert's elements, exploring the perception that local actors have about the extent to which they can make choices.

Exworthy and Frosini (2008), however, argue that, in addition to this 'vertical' granting of decision space (i.e. decentralisation), the exercise of choice by managers in local organisations is shaped by, and depends upon, other actors in the local area. They argue that the realisation of decentralisation is dependent on a local organisation's ability to collaborate with other agencies, over which they have no direct or immediate authority. Yet, at the same time, they must also compete with these agencies for resources (e.g. financial resources from government and human resources from the labour market). Thus, the 'decision space' manifested locally arises from the interactions between 'vertically' granted autonomy and the 'horizontal' realities of acting within a specific local organisational context.

\section{Autonomy and decision space in the NHS}

As discussed in the introduction, the history of the NHS is characterised by repeated rhetorical shifts between the need for decentralisation (lauded as increasing local autonomy) and the need for central control (presented as reinforcing public accountability and fiscal prudence). Thus, for example, the 1983 so-called 'Griffiths reforms' under the Conservative Thatcher government introduced the idea of locally managed 'Units' with general managers and were couched in terms of delegation to these local organisations, but subsequent years saw the introduction of stringent performance review systems, pulling power back towards the centre (Klein, 2013 p114). Allen (2006) explores the more recent history of NHS centralisation/decentralisation, and characterises it as a story of ambivalence, with rhetorical commitment to decentralisation, manifest in the introduction of market mechanisms and autonomous providers, limited in practice by stronger performance management from the centre. The NHS Plan (Secretary of State for Health, 2000) introduced the idea of 'earned' autonomy, by which 'high performing' NHS Trusts were granted a number of freedoms and flexibilities (Mannion et al., 2007), but in practice these 'freedoms' proved something of a mirage, as the need to meet top-down targets tended to dominate subsequently (Bevan and 
Hood, 2006; Macfarlane et al., 2011). Thus, for example, Hoque et al. ( 2004), studied NHS acute hospitals and found that many were ambivalent about exercising decision-making autonomy due to the fear of being made 'scapegoats' if something went wrong.

NHS Foundation Trusts were established in the mid-2000s. These secondary care service providing organisations were intended to be quasi-independent of central government, with additional powers to re-invest surplus income and with local representation in their governance structures (Department of Health, 2005; Dixon et al., 2010). Allen et al (2012) studied the development and governance of NHS Foundation Trusts, finding that they had used their increased vertical autonomy to introduce more business-like practices, with regulators only intervening when problems were reported. However, national-level targets continued to have a significant impact on their work, and they were also constrained horizontally by the need to maintain good relationships with local organisations. It was intended that Foundation Trusts would manifest additional local accountability, with governance by local 'members', but this has proved problematic to realise in practice (Allen et al., 2012). Exworthy et al. (2011) studied Foundation Trusts' willingness and ability to exercise autonomy at three levels: macro; meso; and micro, and found that, whilst they had theoretically gained autonomy from central control, in practice, new forms of economic regulation had partially replaced the previous NHS hierarchy, with Foundation Trusts held to account by Monitor (a health care provider financial regulator, since April 2016 known as NHS Improvement) through a variety of performance and assessment mechanisms. Furthermore, local financial inter-dependencies and the need for local collective action constrained their horizontal autonomy within their local health economies.

Exworthy and Frosini ( 2008) used a similar framework to examine autonomy and decision space in Primary Care Trusts (then responsible for commissioning the majority of NHS services). They explored both the ability and willingness of managers to use their decision space, and found that, amongst other factors, the need to act in a collegiate manner within their local health economies and avoid destabilising significant local providers constrained their autonomy. Furthermore, Primary Care Trust managers were found to be somewhat risk averse, reluctant to use their 'decision space' in case the Department of Health did not approve of their actions. Checkland et al (2012) confirmed this, highlighting the difficulties associated with a market-driven model of commissioning in a system where local actors felt loyalty to one another and to their local area.

Thus, increasing the autonomy of local organisations in the NHS is not straightforward. The granting of administrative freedom to make decisions by no means ensures that this freedom can and will be used, and there is some evidence that an increasing focus on regulation and accountability regimes (Peckham et al., 2005) associated with the granting of greater local autonomy has tended to push managers to act in ways which are risk averse and consonant with the demands of the centre (Macfarlane et al., 2011). In the rest of this paper, we explore the perceptions of CCG clinician leaders and managers about their autonomy, and analyse the extent to which they believe that they have experienced the greater autonomy promised by the HSCA12. In doing this, we explore their perceptions of vertical autonomy - freedom from central control - and horizontal autonomy - freedom to act within their local health economy.

\section{METHODS}


This paper draws on an ongoing study exploring the complexities of the commissioning landscape in England following the HSCA12. The research questions for the study as a whole were based on an analysis of the objectives and mechanisms of the HSCA12, and focus on three issues: system complexity; how commissioning is conducted; and the outcomes of commissioning. For this paper, we focus on the research questions relating to system complexity, in particular, asking: to what extent do local commissioners feel themselves to be autonomous?

In order to explore the interactions between organisations across health economies, two metropolitan areas, corresponding to the geographies of two NHS England Local Area Teams as established in 2013, were selected as sites for the study. NHS England Local Area Teams were, at the time the study started, the local outposts of the newly established NHS England, and each was charged with overseeing the establishment and operation of the commissioning organisations in their area. These conurbations were selected because, although not dissimilar in their geography and socio-economic make up, they had experienced very different degrees of organisational change associated with the implementation of the Act. Thus, the post-Act organisations in Area 1 were similar in size, make up and coverage to those in existence before, whilst in Area 2 many new organisations covering different populations had been established. The areas were also large enough to allow mapping of interactions between multiple commissioners and other organisations, allowing us to explore the complexity of the new system.

This paper reports on the findings from interviews conducted between April 2015 and December 2015. Each area comprised a group of organisations with commissioning responsibilities, including CCGs, Local Authorities (made responsible for public health services from April 2013), NHS England and newly-established Commissioning Support Units, contracted by CCGs to provide managerial support for their commissioning activities. Each organisation was contacted, seeking a senior member of staff for interview. A snowballing approach was employed, asking those interviewed to suggest colleagues in their own or other organisations that might have relevant information. For this paper, we focus upon the findings from 43 interviews carried out with CCG leaders, including senior managers and clinicians. Table 1 provides details of those interviewed. Interview questions focused primarily on the role of interviewees' organisation within the reformed health and social care commissioning system, addressing: recent changes and activities; issues of accountability and autonomy; mechanisms of inter-organisational working; performance management; and the commissioning process itself. We concentrate on the accounts of perceived autonomy provided by CCG leaders.

\section{[table 1 near here]}

Interviews were recorded with consent and transcribed. Transcripts were read repeatedly for familiarisation. An initial coding frame was developed based upon our reading of the underlying policy intentions, focusing upon programme theories identifiable in the suite of policy documents issued to support implementation of the Act. Using the computerised data analysis programme $\mathrm{NVIVO}^{\mathrm{TM}} 9$, segments of text were coded by two members of the research team. Consistency in coding was maintained by frequent discussion of coding 
decisions. Segments of text coded as relating to aspects of 'autonomy' and 'accountability' were extracted and a cross-case analysis undertaken. Aspects of autonomy addressed in the interviews were analysed against the theoretical framework developed above, focusing upon the notion of 'decision space', and the 'vertical' and 'horizontal' dimensions of autonomy explored above. The developing analysis was discussed at team meetings, and memos written to capture the discussions. Emerging findings were fed back to selected interviewees for clarification and to test our interpretations.

Ethical approval from the study was obtained from The University of Manchester in March 2015, and appropriate research governance approvals were sought and obtained for the different organisations involved in the study

\section{RESULTS}

In the following sections, we explore CCG interviewees' perceptions of their autonomy and scope in which to act. We found considerable agreement, with both clinicians and managers telling similar stories, and no systematic differences between the two areas.

\section{Vertical autonomy - decentralisation}

As CCGs took on their new responsibilities, interviewees in both Areas described themselves as having enhanced autonomy compared with their experiences of previous accountability regimes:

Generally speaking, they've allowed us to develop our own priorities and areas of work to focus on, if you like, and then they're assured that in the way I described. It felt very different in the last government because it would nearly always be a top down sort of thing. 2623, CCG manager, Area 1

CCG respondents felt they had autonomy primarily because of their position as statutory bodies, which gave them a sense of legitimacy:

I think we're more autonomous now. ...I guess for a lot of us it was morphing from the role we had into something else but you just step up a bit and the relationships were different because you've got a different relationship with NHS England because that structure changed....... I think there was something about almost we're now legitimate. There's that legitimacy in terms of an organisation 3804, CCG manager, Area 1

Notably, these accounts do not suggest reluctance to exercise autonomy. Our CCG respondents emphasised their appetite for their new role, highlighting an early sense of local power and authority:

..there's been a much bigger impetus to say we want significant change to happen, which people might have tried before but I think now with clinical leadership and clinicians at the forefront I think that's been the benefit, and I think there's almost been an autonomy that we've felt we've had to get on and do what we want to do. So I think we've almost been unleashed a bit since 2013 to 
do things and get on with things on areas we want to do.2338 Clinical leader, Area 1

However, CCG interviewees also explained that their initial sense of increased autonomy had waned over time. For example, CCGs are subject to 'assurance' from NHS England, via an assurance framework (NHS England, 2013), which focuses upon their quality of internal management and financial outcomes, alongside measures of performance such as waiting times, etc. They are also expected to address national priorities, and meet targets over which they potentially have little control:

We have commissioning diktats put down to us, so the operational plan tells us what they expect us to commission or give us a long list of things that they have prioritised for us. I think our flexibility is very limited because we get performance managed on the performance of our local hospital rather than our performance on the things that are the most important to us. So making a decision about [local improvement scheme], if that was one of the things that we've done, we're not performance managed on that. We're performance managed on, did the hospital achieve a 95 per cent target on A\&E? 4519, CCG manager, Area 1

Moreover, over and above the formal and timetabled mechanisms associated with the assurance framework, CCGs were increasingly being asked for ad hoc information to provide evidence for others in the system that all was well:

It's a strange old world. In name and in statute we're an autonomous organisation. On a day-to-day basis it quite often doesn't feel that way. We have very strong steers, particularly from our local team of NHS England. We are constantly given returns to do, data returns, this information, that information. Usually with a 24-hour return if you're lucky and never in the format that you usually produce your information. 7679, CCG manager, Area 2

Some respondents expressed disappointment in the nature of the assurance regime, finding it to be hierarchical rather than collaborative or developmental:

NHS England is different. I think there is still a sort of parent-child relationship [with NHS England]. So, we will be told what to do, so there is a hierarchy in the NHS, and that's how the system's set up...performance is by instruction rather than by sort of development and collaboration. 4096, CCG manager, Area 1

External political pressure was identified as a cyclical factor acting to increase constraint. When asked in mid-2015 whether commissioners felt they had autonomy within their day-today commissioning activities, this was a CCG commissioner's response:

if you'd asked me this 18-months ago, I might have been giving you a different answer, there are certain periods in the political cycle when there is more command and control from the centre and you're probably speaking to me at the 
peak of that time. It's [generally] more adult to adult relationship and less command and control, but there are periods where it moves. 3027, CCG manager, Area 1

Some people stated that they saw the picture positively, i.e. they understand the contexts and the framework, and could make it work by doing what they had to do while also pursuing the things they wanted to do:

I've always felt pretty autonomous anyway, certainly since being in a director's role, because I've been in a director's role for 10 years now and I've always felt a good amount of autonomy to execute whatever I needed to do without too much interference ..... So, you've got a licence to do your role and there's a framework in which to do it and if you stick within that framework, you've got the autonomy to do whatever you want to do within that framework. I'm sure you'll talk to other people and they'll say, no, I think it's far too regulated and authoritarian and every time I want to move I've got to ask for somebody's permission, but I don't feel that, because I plan very carefully..... So, if you keep within the framework, you've got a lot of authority and autonomy to make your decisions. 4446, CCG manager, Area 1

Notably, this manager associated his sense of autonomy with his own tendency and ability to plan his work carefully so as to remain within the boundaries of the system, which required care and skill. In contrast, a number of CCGs stated that the 'must do' things, such as fulfilling short notice requests for performance data reports from NHS England, compromised their capacity to successfully get on with their commissioning work, thereby reducing their autonomy. This was seen as being driven, in part, by the increasing financial challenges in the system:

Over the last couple of years, the process has moved much more into CCGs, essentially, assuring that its providers are delivering to its contract. So, the role has crowded out, I think, the opportunity for clinicians to develop new services to start very much from local needs. It has become much more about a whole system challenge around money, around hitting targets, and CCGs really have lost quite a lot of their autonomy, and we've all been moved along this. 6120, CCG manager, Area 2

\section{Horizontal autonomy- the local environment}

CCGs are operating within an increasingly complex local environment. Following the structural changes enacted in the HSCA12, CCGs are accountable to a plethora of organisations (Checkland et al., 2013). Since 2014, this local environment has further increased in complexity. CCGs have to provide formal accounts to bodies such as local authority Health and Wellbeing Boards, Monitor and local government Health Scrutiny Committees, but are also required or expected to engage with a large number of new bodies and arrangements. The HSCA12 significantly reduced the funding available for the management of CCGs, with the intention that managerial support for commissioning would be 'bought in' from quasi-independent 'Commissioning Support Units' (CSUs). Instead of doing the commissioning work themselves, CCGs are required to procure some services from CSUs (Petsoulas et al., 2014). Respondents told us that these arrangements added additional layers of complexity to their work: 
So I started working with the CSU, but to be quite honest, I mean, I've done quite a bit of commissioning before, there were so many hoops they wanted me to jump through, I was doing all the work and it was, like, they were approving it and you think, well, what's that about? And I was having to pay them to do it basically and they wanted me to do [the work] 16450, Commissioning manager, Area 2

In addition, over the course of the study, CCGs were expected to engage with a range of new bodies which had not been established in the HSCA12, but which were developed on a seemingly ad hoc basis to solve particular issues. These include: System Resilience Groups, set up to provide a forum in which local commissioners and providers can work together to meet system-wide challenges such as winter hospital demand pressures; Urgent and Emergency Care Networks, intended to support urgent care providers in meeting rising demand; Specialised Commissioning Collaboratives, bringing together local commissioners to work with NHS England to commission highly specialised services; and Sustainability and Transformation Plans (STPs), 'place based' inter-organisational arrangements intended to reintroduce some of the regional system coordination lost with the abolition of Strategic Health Authorities. In the STP areas, all local health and care organisations (including Local Authorities, CCGs, NHS England local staff, and secondary and community care providers) are expected to work together to ensure the overall financial sustainability of their area, producing an STPlan in order to qualify to access funding to reduce their financial deficits (NHS England, 2015). Alongside these initiatives, in 2014 NHS England published the Five Year Forward View (NHS England, 2014). This set out NHS England's aspirations for funding and service development, and, inter alia, established a number of 'New Models of Care' known as 'Vanguards' (NHS England, 2016). These are collaborative ventures between commissioners and providers which seek to design and implement new ways of delivering care crossing existing boundaries between primary, secondary, community and social care. Vanguards were commissioned via a national process, and the relationship between local Vanguards and their responsible CCGs are complex and variable, with some closely involved whilst others are not. Finally, many CCGs have decided to work together and with relevant providers informally on a variety of scales and in different combinations. These are sometimes referred to as 'networks' or 'sectors', and may, for example, include combining forces to jointly commission some services, or working across the boundaries between commissioners and providers to tackle complex service issues. Taken together, and with Exworthy and Frosini's (2008) 'horizontal' dimension of autonomy in mind, this sprawling range of inter-organisational arrangements clearly suggests that CCGs' freedom to act, even if they have formal autonomy from the centre, is likely to be limited by the need to co-ordinate, collaborate and interact with other local actors.

The development of these inter-organisational arrangements was emergent and on-going during data collection. In this constantly changing situation, interviewees often struggled to express what particular groups or initiatives were intended to achieve or what their role in them was meant to be.

[System Resilience Groups/SRGs were introduced] I think, about two years ago, but their role has evolved quite dramatically. So, they were, initially....quite permissive, their remit, and, now, it's much more about this is who we expect to be on there, this is what we want you to do, this is how we can expect you to 
monitor it, this is by when, and there's a cascade of, almost, weekly edicts for the SRGs to provide assurance. ... then there'll be a meeting to check what you're saying is right, and this kind of environment, it, increasingly, feels adversarial, and the level of expectation feels quite unrealistic as well. 6120, CCG manager, Area 2

The initiatives mentioned exist at different scales and cover different populations. One CCG clinician was critical of the Urgent and Emergency Care Network model on the basis that the Network with which his CCG was associated did not correspond to any other relevant geographical boundaries. It represented yet another responsibility that the CCG was required to discharge at a broad scale, which contrasted particularly with the local focus that CCGs were created to attend to:

But then you've got your SRGs, which sits around [Place X] and [Place Y], so that maps reasonably well. You've got these new unfathomable Urgent Care Networks over a geography that makes no sense whatsoever... They sit above the SRGs, but there's no logical sense to my mind as to why they exist and what they're going to exist to do, and how they can be of any use in the footprints that they sit at. 6165, CCG manager, Area 2

Not only were these developing arrangements complicated to negotiate, they also had an impact on other organisations trying to work in partnership with the NHS:

...we've got so much complexity, and in fact we keep adding to it, so the Five Year Forward View has now introduced a whole bunch of new types of ballgame, we've got Vanguards, we've got different collaborations, we've now got new networks, we've got Senates. There's been a proliferation of organisational arrangements and network arrangements which must make it almost bewilderingly complex, I would have thought, to anyone who's got to try and partner with the NHS. It's making us a very difficult partner to work with, despite our best efforts. 6010, CCG manager, Area 2

As well as being more structurally complex the new system was also functionally more complex. Prior to the HSCA12, Primary Care Trusts were responsible for the majority of commissioning activity. Following the HSCA12, responsibilities were split between CCGs, Local Authorities, NHS England and Public Health England. This placed an onus on CCGs to work closely with all these organisations in order to ensure co-ordination across care 'pathways':

you know, how do you come back together as a system where commissioning responsibilities are shared now across a number of different organisations? If what you're wanting to do is work, you know, in a neighbourhood, looking at real outcomes and getting your GPs, your social workers, everybody to work together, it does then require those commissioners to come together and agree a different outcomes framework for all of those things. So it's not impossible and we've done a lot of work in terms of integrating our commissioning arrangements with the local authority but it's just an added complexity isn't it really? 3665, CCG manager, Area 1 
This manager looked back nostalgically to the days in which an over-arching organisation provided some degree of co-ordination, in contrast to a system with many autonomous organisations all with statutory authority:

Part of the difficulty is that because we're all statutory bodies nobody can actually impose their will. There's no-one who can say, well, this is what we're going to do, because the role of NHS England is different now. They assure us as individual CCGs. The provider trust, it's a foundation trust so they're accountable to NHS Improvement - they're not accountable to NHS England. NHS England, we are accountable to them through an assurance process but not a direct line management responsibility. So it's different to how the S[trategic] H[ealth] A[uthority] would have dealt with this. If we still had an SHA the SHA chief executive would have convened a discussion, would have sorted it out and would have directed people to act in a certain way. 10648 CCG manager Area 2

\section{Discussion}

Taking both vertical and horizontal dimensions of autonomy together, this study suggests that, far from being more autonomous than their predecessor organisations, those interviewed reported that CCGs' decision space had become progressively limited. In the vertical dimension, this had been driven by an increasingly strict and prescriptive assurance regime, and early enthusiasm, driven by a sense of legitimacy and authority, had become tempered by a growing sense of constraint. In the horizontal dimension, the proliferation of new organisations, care models, networks and forums meant that the local environment in which CCGs operated was equally constraining. Comparing our findings with those from previous research in the NHS, we found that, rhetorically at least, CCG leaders had initially expressed an appetite for autonomy which seemed historically to be at least partially missing in Primary Care Trusts (Exworthy and Frosini, 2008) and Foundation Trusts (Exworthy et al., 2011). Furthermore, whilst CCGs appear to be as constrained in the horizontal direction as their predecessor organisations, the focus appears to have shifted somewhat, moving away from constraint based upon local solidarity and the need to avoid 'destabilising' partner organisations (Allen, 2006; Exworthy and Frosini, 2008) to constraint rooted in the sheer volume of local connections, networks and inter-organisational interactions. Taken together, these findings suggest that CCGs are operating within a limited 'decision space', albeit constrained in a somewhat different way than in the past.

More generally, the finding that a policy commitment to local autonomy and decentralisation had faltered in the face of the complexities of service delivery in a resource-constrained environment is perhaps unsurprising. Indeed, it is consonant with the political history of the NHS as told by Klein (2013), who documents in detail repeated cycles of centralisationdecentralisation - sometimes occurring simultaneously (Allen, 2006) - since the inception of the NHS (Klein, 2013). International studies confirm similar cycles in other jurisdictions, with clear evidence that decentralisation in health systems is neither a panacea nor an uncomplicated good (Mosca, 2005). De Vries (2000 p203) refers to the 'fantasy of optimum scale', suggesting that the pendulum swings seen across many health care systems result from 
a somewhat vain attempt to optimise the level at which control should occur, with a general tendency for more central control occur if resources are scarce.

This study also confirms that the 'radical simplification' (Department of Health, 2010 p43) which the English reforms were intended to deliver did not materialise, with fragmentation of responsibilities a particular issue highlighted by our respondents. It is particularly striking how significantly local horizontal relationships have increased and become more complex compared with the situation pre-HSCA12, with CCGs existing in a local context dominated by the rapid invention of organisations, groups and networks with novel and overlapping boundaries and remits. At the time of Exworthy and Frosini's (2008) research, Primary Care Trusts' key relationships were with their service providers and with their Local Authorities, with whom they jointly commissioned some services. CCGs, by contrast, have a multitude of new bodies with which they must interact, including CSUs, System Resilience Groups, Urgent and Emergency Care Networks, Vanguards and STPs, some of which increased the pressure on CCGs by peppering them with demands for data and evidence to prove that all was well within the local system. Many of these were not part of the original vision embodied in the HSCA12, which sought to 'radically delayer' the NHS (Department of Health 2010 p5), reducing the number and scope of meso-level organisations. Prior to the Act, Strategic Health Authorities had carried the responsibility for: 'creating a coherent strategic framework for the development of services across the full range of local NHS organisations' (Department of Health, webarchive) This included maintaining overall system integrity, supporting and performance managing Primary Care Trusts, and co-ordinating service delivery to ensure financial balance was maintained across a geographical area. It is notable that many of the new bodies and forums created since the Act appear to be designed to reinvent some of these functions. In particular, the development of 'System Resilience Groups', along with varying and inconsistent demands from a variety of central bodies for data to prove that organisations are meeting their obligations, speak to a need for meso-level coordination in case of organisational failure. At the same time, the development of STPs seems to acknowledge the need for a regional tier of organisation that can take an overview of the health and care system across an area, thereby ensuring system integrity, and balancing the needs of commissioners and providers. Thus it would seem that, whilst the idea of local organisational autonomy carries within it the promise of responsiveness and efficiency, increasingly complicated health care systems require meso-level co-ordination to ensure system integrity.

Our data cover a short period of time but one during which local organisations and relationships were changing rapidly; it is therefore likely that our description of local realities will be partial and rapidly out of date. In addition, we report perceptions based upon interview responses. The collection of more detailed observational data would have allowed us to capture in more depth the nuances of local autonomy, unpicking the topic areas in which more or less autonomy was experienced. Nevertheless, we believe that our broad conclusions remain valid.

\section{Conclusions}

The overall story told in our two areas was strikingly similar: an initial appetite for newly granted autonomy constrained vertically by an increasingly onerous managerial assurance regime, and constrained horizontally by a proliferation of bodies, networks and forums with 
varied and sometimes overlapping remits. Overall, our study suggests that decentralisation requires some degree of regional co-ordination and oversight by an organisation able to 'hold the ring' and support the myriad of local bodies which must work together to deliver increasingly complicated services in a resource-constrained environment.

There is currently little available research which explores the role of meso-level organisations in health systems. Focusing more generally on requirements for inter-organisational coordination in complex organisational fields, Alexander argues that:

Inter-organisational Coordination (IOC) is the process of coordinating the decisions and actions of several organizations, for a purpose or undertaking that no one of them can accomplish alone. This also accounts for the need for IOC, which arises in situations demanding concerted action for the mutual purposes of the organizations involved. (Alexander, 1998 p342)

This formulation neatly describes the situation in the case study areas, with the need for concerted action driving the proliferation of meso-level coordinating mechanisms and bodies in an apparently ad hoc and unplanned manner. The recent development of Sustainability and Transformation Partnerships (STPs) in England, charged with developing a regional placebased over-arching plan for local services, would seem to be a response to the somewhat chaotic landscape that we have described. However, STPs have no statutory footing, and their plans have been developed without local public input (Black and Mays, 2016; Walshe, 2017). Research is urgently required to explore in more depth the factors affecting the success or failure of attempts at regional coordination; this may be an area in which health systems can learn from other areas of public policy, and the UK can learn from other jurisdictions. Relevant areas for further exploration include: how best to maintain the balance between the motivating effect of local autonomy and the need for a degree of pooled sovereignty at regional level; the extent to which statutory authority is necessary for effective coordination; and the degree of discretion required at regional level to facilitate effective local cooperation. As plans to devolve responsibility for aspects of health and social care services to local areas gather pace in England (Checkland et al., 2016b; Walshe et al., 2016), this last issue requires urgent attention.

\section{References}

Alexander, E.R. (1998), 'A structuration theory of interorganizational coordination: cases in environmental management', The International Journal of Organizational Analysis, 6: 4, 334-354.

Allen, P. (2006), 'New localism in the English National Health Service: What is it for?', Health Policy, 79: 2-3, 244-252.

Allen, P., Keen, J., Wright, J., Dempster, P., Townsend, J., Hutchings, A., Street, A. and Verzulli, R. (2012), 'Investigating the governance of autonomous public hospitals in England: multi-site case study of NHS foundation trusts', Journal of Health Services Research \& Policy, 17: 2, 94-100.

Axelsson, R. (2000), 'The organizational pendulum: Healthcare management in Sweden 1865 -1998', Scandinavian Journal of Public Health, 28: 1, 47-53.

Bevan, G. and Hood, C. (2006), 'What's measured is what matters: targets and gaming in the english public health care system', Public Administration, 84: 3, 517-538. 
Black, N. and Mays, N. (2016), 'Sustainability and transformation plans: a troubled start', $B M J, 355$.

Bossert, T. (1998), 'Analyzing the decentralization of health systems in developing countries: Decision space, innovation and performance', Social Science and Medicine, 47: 10, 1513-1527.

Cambridge online dictionary. (http://dictionary.cambridge.org/dictionary/english/autonomy) accessed 7/4/17

Checkland, K., Harrison, S., Snow, S., McDermott, I. and Coleman, A. (2012), 'Commissioning in the English National Health Service: What's the Problem?', Journal of Social Policy, 41: 03, 533-550.

Checkland, K., Allen, P., Coleman, A., Segar, J., McDermott, I., Harrison, S., Petsoulas, C. and Peckham, S. (2013), 'Accountable to whom, for what? An exploration of the early development of Clinical Commissioning Groups in the English NHS', BMJ Open, 3: 12.

Checkland, K., McDermott, I., Coleman, A. and Perkins, N. (2016a), 'Complexity in the new NHS: longitudinal case studies of CCGs in England', BMJ Open, 6: 1.

Checkland, K., Segar, J., Voorhees, J. and Coleman, A. (2016b), 'Like a Circle in a Spiral, Like a Wheel within a Wheel': The Layers of Complexity and Challenge for Devolution of Health and Social Care in Greater Manchester', Representation, 1-17.

De Vries, M.S. (2000), 'The rise and fall of decentralization: A comparative analysis of arguments and practices in European countries', European Journal of Political Research, 38: 2, 193-224.

Department of Health (2005), A short guide to NHS Foundation Trusts, London: The Stationary Office.

Department of Health (2010), Equity and Excellence: liberating the NHS, London: The Stationary Office.

Department of Health (webarchive)

(http://webarchive.nationalarchives.gov.uk/+/www.dh.gov.uk/en/Publicationsandstati stics/Publications/PublicationsPolicyAndGuidance/Browsable/DH_4949934). online resource, accessed 7/4/17

Dixon, A., Storey, J. and Alvarez Rosete, A. (2010), 'Accountability of Foundation Trusts in the English NHS: Views of Directors and Governors', Journal of Health Services Research \& Policy, 15: 2, 82-89.

Exworthy, M. and Frosini, F. (2008), 'Room for manoeuvre?: Explaining local autonomy in the English National Health Service', Health Policy, 86: 2-3, 204-212.

Exworthy, M., Frosini, F., Jones, L., Peckham, S., Powell, M., Greener, I., Anand, K. and Holloway, J. (2010), Decentralisation and Performance: Autonomy and Incentives in Local Health Economies: NIHR Service Deliery and Organisation Programme.

Exworthy, M., Frosini, F. and Jones, L. (2011), 'Are NHS foundation trusts able and willing to exercise autonomy? 'You can take a horse to water...', Journal of Health Services Research \& Policy, 16: 4, 232-237.

Harrison, S. and Ahmad, W.I.U. (2000), 'Medical autonomy and the UK state 1975 to 2025', Sociology, 34: 1, 129-146.

Hoque, K., Davis, S. and Humphreys, M. (2004), 'Freedom to do What you are Told: Senior Management Team Autonomy in an NHS Acute Trust', Public Administration, 82: 2, 355-375.

Klein, R. (2013), The new politics of the NHS: from creation to reinvention (7th edition), London: Radcliffe Publishing Ltd. 
Macfarlane, F., Exworthy, M., Wilmott, M. and Greenhalgh, T. (2011), 'Plus ça change, plus c'est la même chose: senior NHS managers' narratives of restructuring', Sociology of Health \& Illness, 33: 6, 914-929.

Mannion, R., Goddard, M. and Bate, A. (2007), 'Aligning incentives and motivations in health care: the case of earned autonomy', Financial Accountability \& Management, 23: 4, 401-420.

Mosca, I. (2005), 'Is decentralisation the real solution?', Health Policy, 77: 1, 113-120.

NHS England (2012) Health and Social Care Act 2012: Fact Sheets https://www.gov.uk/government/publications/health-and-social-care-act-2012-fact$\underline{\text { sheets }}$

NHS England (2013), Draft framework of excellence in clinical commissioning, Nov 2013.

NHS England (2014), Five year forward view, Leeds: NHS England.

NHS England (2015), Delivering the Forward View: NHS planning guidance 2016/17 to 2020/21 Leeds: NHS England.

NHS England (2016), The forward view into action: New Care Models: update and initial support, Leeds: NHS England.

Peckham, S., Exworthy, M., Greener, I. and Powell, M. (2005), 'Decentralizing Health Services: More Local Accountability or Just More Central Control?', Public Money \& Management, 25: 4, 221-228.

Petsoulas, C., Allen, P., Checkland, K., Coleman, A., Segar, J., Peckham, S. and McDermott, I. (2014), 'Views of NHS commissioners on commissioning support provision. Evidence from a qualitative study examining the early development of clinical commissioning groups in England.', BMJ Open, 4: e005970.

Powell, M. (2016), 'Order of change in the ordered changes in the NHS', in M. Exworthy, R. Mannion and M. Powell (eds.), Dismantling the NHS? Evaluating the impact of health reforms, Bristol: Policy Press.

Secretary of State for Health (2000), The NHS plan: a plan for investment, a plan for reform, London: The Stationary Office.

Speed, E. and Gabe, J. (2013), 'The Health and Social Care Act for England 2012: The extension of 'new professionalism", Critical Social Policy, 33: 3, 564-574.

Timmins, N. (2012), Never again? The story of the Health and Social Care Act 2012. A study in coalition government and policy making. , London The King's Fund.

Verhoest, K., Peters, B.G., Bouckaert, G. and Verschuere, B. (2004), 'The study of organisational autonomy: a conceptual review', Public Administration and Development, 24: 2, 101-118.

Walshe, K., Coleman, A., McDonald, R., Lorne, C. and Munford, L. (2016), 'Health and social care devolution: the Greater Manchester experiment', BMJ : British Medical Journal (Online), 352.

Walshe, K. (2017), 'Sustainability and transformation plans for the NHS in England: radical or wishful thinking?', BMJ, 356.

Weiss, C.H. (1999), 'The Interface Between Evaluation and Public Policy', Evaluation, 5: 4, 468-486. 
Table 1: Number of CCG interviews in each area by interviewee role type

Area 1

Area 2

\begin{tabular}{llll}
\hline Role type & $\begin{array}{l}\text { No. of } \\
\text { interviews }\end{array}$ & Role type & $\begin{array}{l}\text { No. of } \\
\text { interviews }\end{array}$ \\
\hline Clinical leader & 7 & Clinical leader & 7 \\
Senior manager & 20 & Senior manager & 9 \\
\hline Total & $\mathbf{2 7}$ & & $\mathbf{1 6}$
\end{tabular}

Figure 1: Decision space approach

(adapted from Bossert 1998: p1514)

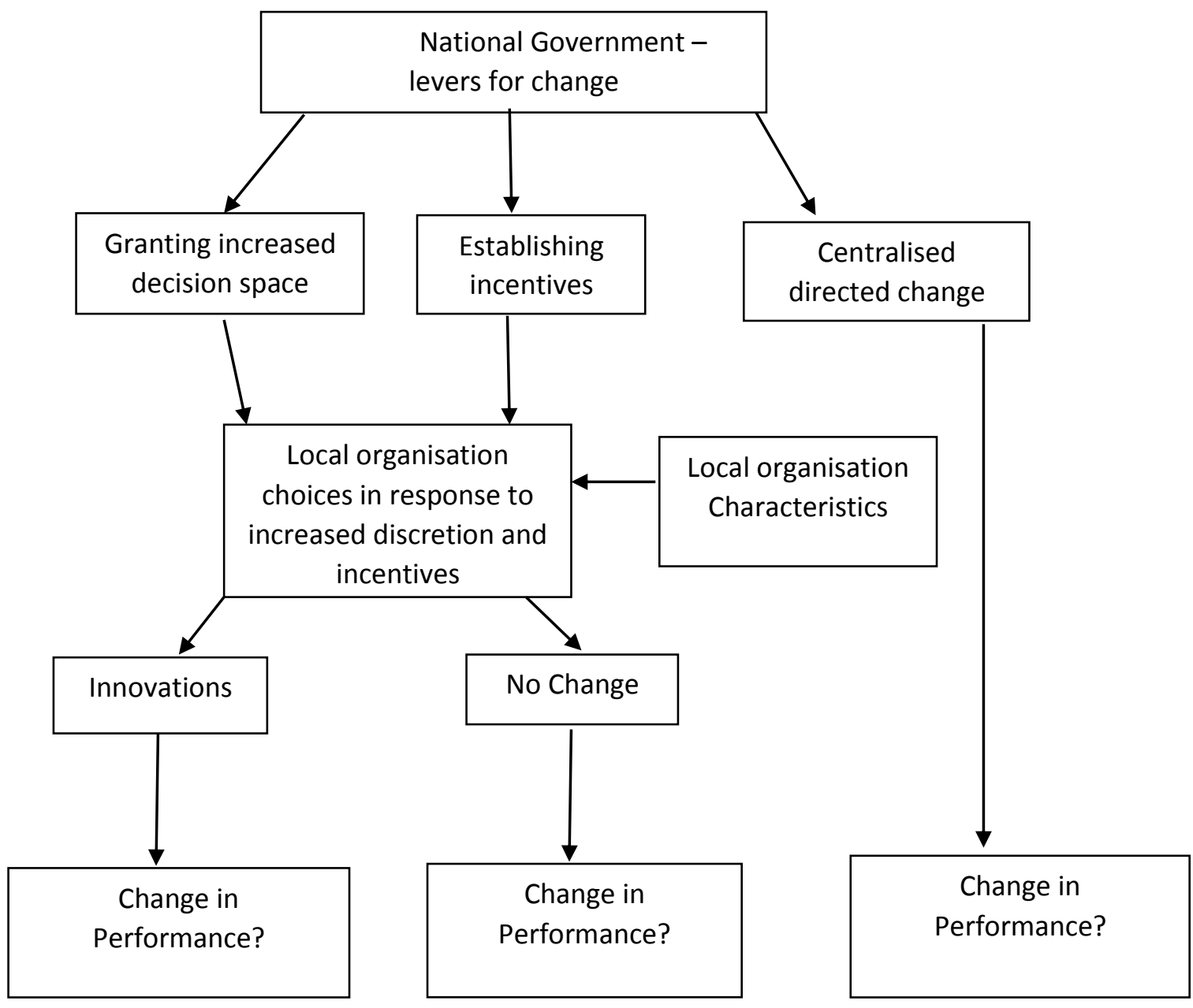

